\title{
Etapas de diagnóstico da metodologia de planejamento e gestão de arranjos socioprodutivos de turismo comunitário: a experiência da Microbacia do Rio Sagrado (Morretes, Brasil) ${ }^{1}$
}

\section{Diagnostic phases of the methodology of planning and management of social sector arrangements of community tourism: The experience of Rio Sagrado watershed (Morretes, Brazil)}

\author{
Gabriela Zamignan (ZAMIGNAN, G) ${ }^{*}$, \\ Carlos Alberto Cioce Sampaio (SAMPAIO, C. A. C.) ${ }^{* *}$ e \\ Oklinger Mantovaneli Jr. (MANTOVANELI JÚNIOR, O.) ${ }^{* * *}$
}

\begin{abstract}
RESUMO - Atualmente muitas comunidades vêm se destacando por novas formas de organização, em busca do fortalecimento de suas identidades, seja nos espaços sociopolíticos e socioprodutivos. Neste limiar, surgem os arranjos socioprodutivos de turismo de base comunitária coerentes com um novo estilo de desenvolvimento territorial sustentável. O presente trabalho analisa a experiência do Arranjo Socioprodutivo de Turismo de Base Comunitária da Microbacia do Rio Sagrado, situado no município de Morretes (Paraná, Brasil), com intuito de discutir o arranjo, por meio da aplicação das etapas de diagnóstico da metodologia Planeação Estratégica e Comunicativa (PEC) e Gestão Organizacional para o Desenvolvimento Territorial Sustentável (SiGOS) que promove Arranjos Socioprodutivos do Turismo de Base Comunitária (APTur.Com). Dentre os principais resultados, confirma-se que o diagnóstico possibilita pensar sistemicamente a estrutura de arranjos sociopolíticos e socioprodutivos e vislumbra a inclusão da economia comunitária na economia de mercado, no entanto, preservando sua dinâmica própria.
\end{abstract}

Palavras-chave: Arranjo Socioprodutivo; Diagnóstico; Metodologia PEC/SiGOS; Desenvolvimento Territorial.

ABSTRACT - Nowadays many communities have stood out by new kinds of organization, seeking to strengthen their identities, such as in sociopolitical and socio sector spaces. Thus appear the social sector arrangements for community-based tourism coherent with a new style of sustainable territorial development. This paper analyzes the experience of the social sector arrangements for community-based tourism in the Rio Sagrado Watershed, Morretes (Paraná, Brazil), aiming to discuss the arrangement, by applying the diagnostic phases of the Strategic and Communicative Planning (PEC) and Organizational Management for Sustainable Territorial Development SiGOS) methodologies which promote social sectors arrangement for community-based tourism (APTur.Com). Among the main results, it is confirmed that the diagnostic makes possible to think systematically the structure of the sociopolitical and social sector arrangements and includes the communitarian economy in the market economy, however, preserving its own dynamics.

Key words: Social Sector Arrangements; Diagnostic; Strategic and Communicative Planning (PEC)/Organizational Management for the Sustainable Territorial Development (SiGOS) Methodologies; Territorial development.

\footnotetext{
${ }^{1}$ A versão preliminar deste artigo foi apresentada no VIII Seminário da Associação Nacional de Pesquisa e Pós-Graduação em Turismo, de 02 e 04 de outubro de 2011 - UNIVALI - Balneário Camboriú (SC).

* Graduação em Turismo pela Fundação Universidade Regional de Blumenau (FURB). Mestranda do Programa de Pós-Graduação em Meio Ambiente e Desenvolvimento da Universidade Federal do Paraná (UFPR). Pesquisadora do Núcleo de Políticas Públicas/PPG em Desenvolvimento Regional (FURB). Bolsista da Coordenação de Aperfeiçoamento de Pessoal de Nível Superior - CAPES. Endereço: Rua Alfredo Bufren, 285 (Centro). CEP: 80020-240 - Curitiba - Paraná (Brasil). Telefone (41) 9635-4700. Email: gabinhaaa_@hotmail.com

*** Graduação em Administração pela Pontifícia Universidade Católica de São Paulo (PUC-SP). Mestrado em Administração Pública pela Universidade Federal de Santa Catarina (UFSC). Doutorado em Engenharia de Produção (UFSC) com sandwich em Economia social (EHESS/Paris). Professor do PPG em Meio Ambiente e Desenvolvimento (UFPR) e Desenvolvimento Regional (FURB). Pesquisador junto ao Conselho Nacional de Desenvolvimento Científico e Tecnológico - CNPq. Endereço Postal: Rua Gabriela Mistral, 263. CEP: 80540-150 - Curitiba - Paraná (Brasil). Telefone (41) 3029-7208. E-mail: carlos.cioce@ gmail.com

**** Graduação em Relações Internacionais pela Universidade de Brasília (UNB). Mestrado em Administração Pública (UFSC). Professor do PPG em Desenvolvimento Regional (FURB). Endereço: Universidade Regional de Blumenau - Programa de PósGraduação em Desenvolvimento Regional - Núcleo de Políticas Públicas, Rua Antônio da Veiga, 140, Victor Konder. CEP: 89012900 - Blumenau - Santa Catarina (Brasil). Telefone (47) 8416-3458. E-mail: oklinger@furb.br
} 


\section{INTRODUÇÃO}

Atualmente as atenções mundiais estão focadas nas questões sobre a problemática socioambiental instaurada. Diante dessa problemática que Sachs (1986) aponta a necessidade de um enfoque de planejamento que incorpore premissas de desenvolvimento mais sustentáveis, primando por relações mais harmônicas entre sociedade, economia e natureza e, ao mesmo tempo, favorecendo que ações sejam reavaliadas e novas iniciativas de desenvolvimento se projetem.

Para tanto, muitas comunidades vem se destacando por novas formas de organização, em busca do fortalecimento de suas identidades, seja nos espaços sociopolíticos (associações civis e os movimentos sociais) e socioprodutivos (como as cooperativas e empreendimentos comunitários). Assim, por meio de aplicações das metodologias de planeação estratégica e comunicativa (PEC) e gestão organizacional estratégica (SiGOS), pode-se adquirir conhecimentos e informações que permitam sugerir princípios de gestão social que superem a ótica puramente econômica e utilitarista.

Neste sentido, o presente trabalho ilustrou-se com a experiência do Arranjo Socioprodutivo do Turismo de Base Comunitária (APLTur.Com) do Sudoeste da Microbacia do Rio Sagrado, situado no município de Morretes (Paraná, Brasil), o qual coaduna com a perspectiva do desenvolvimento territorial sustentável. Para tanto, pretendeu-se discutir o arranjo, por meio da aplicação da metodologia PEC-SiGOS, e os principais resultados obtidos a partir do trabalho realizado com os membros comunitários na construção do APLTur.Com do Rio Sagrado.

\section{ARRANJOS SOCIOPRODUTIVOS DE TURISMO DE BASE COMUNITÁRIA}

Para o entendimento do que são APLTur.Com é essencial compreender o conceito de Arranjo Produtivo Local (APL). O APL é caracterizado pela existência da aglomeração de um número significativo de empresas que atuam em torno de uma atividade produtiva principal (ALBAGLI \& BRITO, 2002), bem como de empresas correlatas e complementares como fornecedoras de insumos e equipamentos, prestadoras de consultoria e serviços, comercializadoras, clientes, entre outros, em um mesmo espaço geográfico (um município, 
conjunto de municípios ou região), com identidade cultural local e vínculo, mesmo que incipiente, de articulação, interação, cooperação e aprendizagem entre si e com outros atores locais e instituições públicas ou privadas de treinamento. Cassiolato e Szapiro (2002) indicam que tais arranjos apresentam fortes vínculos envolvendo agentes localizados no mesmo território, sendo que estas interações se referem não apenas a empresas e suas diversas formas de representação e associação, mas também a diversas outras instituições públicas e privadas.

Conforme apontam Becker e Léna (2003), o surgimento de pequenos empreendimentos incentivados pelas políticas de desenvolvimento sustentável, são caracterizados pela ligação entre os recursos naturais e as culturas locais, formados por associações locais e pequenos projetos, com objetivo de fomentar uma nova dinâmica econômica no tecido social, beneficiando as populações regionais e promovendo a melhoria da qualidade de vida das comunidades participantes.

Os autores explicam que esses empreendimentos se diferem dos convencionais em função do tipo de sustentabilidade em questão, pelas múltiplas interações entre os atores e pela forma de valorização das singularidades dos agentes envolvidos, gerando um verdadeiro "tecido produtivo". Estes empreendimentos têm como finalidade a proposição de uma economia alternativa, como economia popular ou solidária, com base nos valores de igualdade, solidariedade, compromisso com a preservação do meio ambiente e democracia participativa (BECKER \& LÉNA, 2003).

Quanto ao Turismo Comunitário ou de Base Comunitária (TBC), pode ser definido como aquele "[...] desenvolvido pelos próprios moradores de um lugar que passaram a ser os articuladores e os construtores da cadeia produtiva, onde a renda e o lucro ficam na comunidade e contribuem para melhorar a qualidade de vida" (CORIOLANO, 2003, p. 41). Neste sentido, uma das principais características do turismo comunitário é construir um modelo mais justo e equitativo de turismo, que considera as mais diversas dimensões da sustentabilidade, colocando a comunidade local no centro do planejamento, da implementação e coordenação da atividade turística, oportunizando a geração de benefícios para a melhoria da qualidade de vida da população local.

Turismo de base comunitária (TBC) tem como maior desafio aumentar a autoestima das comunidades autóctones, normalmente identificadas como populações tradicionais, de maneira a fazer crer que seus modos de vida são dignos, mesmo quando estes não propiciam ou 
não são simbolizados pelo padrão de consumo do modo de vida tipicamente urbano (SAMPAIO, 2010).

TBC e arranjos socioprodutivos de base comunitária (APL.Com) são constructos que se complementam. Enquanto que o TBC privilegia modos de vida o APL.Com se baseia nos modos de produção, compreendendo toda a cadeia socioprodutiva.

Neste limiar, surge a denominação de APLTur.Com - Arranjo Socioprodutivo de Turismo de Base Comunitária, com intuito de enfatizar os aspectos institucionais bem como a participação e envolvimento comunitário. O APLTur.Com é um microempreendimento compartilhado no qual se vislumbra a possibilidade de superação da competitividade utilitarista econômica e se privilegiam ações no âmbito de uma rede horizontal de cooperação (SAMPAIO et al., 2005). Assim, pode-se citar que os APLTur.Com configuram redes de organizações socioprodutivas locais, qualificadas como associativas, comunitárias ou de socioempreendedorismo individual, que precedem responsabilidade socioambiental. Dentre os principais benefícios obtidos pelo funcionamento de um APLTur.Com, pode-se destacar que a valorização das sinergias coletivas através da aglomeração de empreendimentos, bem como a relação destas com o meio ambiente, oportuniza o desenvolvimento do arranjo e constitui-se como uma fonte de vantagens competitivas a longo prazo (SAMPAIO; ZECHNER; ALVES, 2008).

O APLTur.Com aposta no princípio de que pode existir solidariedade na economia entre os que se associam, para produzir, comercializar e consumir produtos, inspirados na perspectiva da economia solidária. Sampaio et al. (2005) propõem que a composição de um APLTur.Com envolve e desencadeia um conjunto de outras microrredes, sendo que a principal microrrede não é a mais importante, mas possui a função de incubar as demais, conforme demonstra a Figura 1.

\begin{tabular}{c|c|c} 
& $\begin{array}{c}\text { Encadeamento Produtivo Vertical (à } \\
\text { montante) }\end{array}$ & \\
\hline $\begin{array}{c}\text { Encadeamento Produtivo Horizontal } \\
\text { (organização de apoio) }\end{array}$ & Microrrede Principal & $\begin{array}{c}\text { Encadeamento Produtivo Horizontal } \\
\text { (terceirização não espúria) }\end{array}$ \\
\hline & $\begin{array}{c}\text { Encadeamento Produtivo Vertical (à } \\
\text { jusante) }\end{array}$ &
\end{tabular}

FIGURA 1 - MICROESTRUTURAARRANJO SOCIOPRODUTIVO DE BASE COMUNITÁRIA FONTE: Baseado em SAMPAIO (2010). 
$\mathrm{Na}$ constituição dessa rede existem encadeamentos verticais, sendo que a relação principal entre fornecedor-produtor situa-se para trás (à montante), e a relação entre produtordistribuidor para frente (à jusante); também ocorrem encadeamentos horizontais situados entre produtores terceirizados. As redes institucionais se estabelecem no nível local e regional, fomentando toda a cadeia vertical e horizontal (SAMPAIO, MUNDIM, DIAS, 2004; SAMPAIO, 2010).

Aperfeiçoando a tecnologia social do APLTur.Com, a experiência paradigmática de cooperativismo de Mondragón ${ }^{2}$ remete a alguns aprendizados: holding cooperativa que assessora iniciativas de desenvolvimento de novos socioempreendimentos e presta serviços técnico, jurídico ou financeiro; congresso associativo que discute, de tempo em tempo, a visão institucional da experiência; banco de microcrédito, bem como sistema de assistência e previsão social próprio; organizações que se estruturam como sistema setorial (artesanato ou turismo comunitário) ou por laços territoriais (microbacia ou comunidades), por encadeamentos verticais e horizontais; fundos intercooperativos com finalidade primordial de garantir partilha homogênea e solidária de benefícios na realização de projetos individuais e coletivos de socioempreendimentos; parcerias com instituições de ensino, pesquisa e desenvolvimento e inovação (SAMPAIO et al., 2010a).

O desafio do APLTur.Com é criar e manter gestão participativa corporativa sob signo de identidade que gere sentimento de pertencimento e facilite a intercooperação e se expanda à identidade cooperativa no plano político-institucional e na gestão organizacional. Assim, é imprescindível que tal estilo inicie desde os órgãos de governança até a gerência, considerando que a participação qualifica melhor a tomada de decisão (sem correr riscos do assembleísmo) e media a tensão entre associados.

O APLTur.Com dinamiza ofícios baseados em atividades que se utilizam de tecnologias apropriadas ou que se valem da produção artesanal, geralmente excluídos ou, então, menosprezados nas cadeias produtivas convencionais. O movimento Comércio Justo é uma iniciativa nesta direção, como vem demonstrando inovações nos bens e serviços, como os ecodesigners, que vem agregando valor a conceitos já conhecidos.

\footnotetext{
${ }^{2}$ O cooperativismo de Mondragón, País Basco, Comunidade Autônoma da Espanha, é considerado a maior experiência de corporação cooperativa multisetorial do mundo, compreendendo um grupo industrial (metalúrgicas, empresas de bens de consumo), de distribuição (hipermercados, agências de viagens), de conhecimento (universidade, institutos de pesquisa) e financeiro (banco, seguridade social), além de seus desdobramentos e de suas imbricações. É o $7^{\circ}$ maior grupo privado empresarial espanhol, com cerca de 100.000 trabalhadores (muitos deles cooperados), tendo renda per capita e índice de desenvolvimento humano mais elevado do que a média dos países da União Européia (SAMPAIO et al., 2010a).
} 


\section{COMPREENDENDO A METODOLOGIA PEC/SIGOS/APL.COM}

A Planeação Estratégica e Comunicativa (PEC) tem sua ênfase na elaboração de estratégias e a Gestão Organizacional Estratégica para o Desenvolvimento Sustentável (SiGOS) tem sua ênfase na implementação de estratégias. Assim, quando aplicadas conjuntamente, se qualificam para fomentar um APLTur.Com. O APLTur.Com prescinde não só dos vetores eficiência e eficiência interorganizacional, mas de efetividade extra-organizacional (territorial).

O eixo central e comum das duas metodologias baseia-se no pressuposto de que os indivíduos têm potencialidades que estas devem ser valorizadas e aproveitadas para a melhoria de sua vida. Em outras palavras, as experiências com as metodologias PEC/SiGOS exemplificam e demonstram que absorver, sistematizar e potencializar o conhecimento popular local possibilita constituir arranjos institucionais tão necessários para a promoção do desenvolvimento local. Trata-se da "utilização do conhecimento adquirido de experiências empíricas a partir do viver subjetivo das pessoas e que é utilizado objetivamente no cotidiano delas" (SAMPAIO; FERNANDES; PHILIPPI JR, 2010, p. 34).

A metodologia hibrida PEC e SiGOS, pensada especificamente para o turismo de base sustentável, induz um conjunto de adaptações a partir do modelo original normalmente aplicado. Esse conjunto de adaptações evidencia a ênfase interorganizacional e micro espacial considerando a realidade socioeconômica e a abordagem do APL.Com, a partir das quais emerge a proposta de um arranjo socioprodutivo de base comunitária, aproveitando o modelo híbrido PEC/SiGOS e suas etapas (SAMPAIO; FERNANDES; PHILIPPI JR, 2010)

As etapas 1 - Arranjo Institucional - e 2 - Visão e Missão - da metodologia original PEC e SiGOS estão suficientemente preparadas para lidar com a ênfase interorganizacional e micro espacial socioeconômica. Nesse sentido, tendo em conta o turismo de base comunitária, os atores convidados devem representar o trade que engloba o arranjo socioprodutivo de base comunitária de maneira que não só atores sociopolíticos sejam representados, como ilustra a figura 1. A etapa 3 - Ambiente Externo e Interno -, além das oficinas presenciais, deve considerar, também, uma lista das oportunidades, ameaças, pontos fortes e fracos sugerida pelos demandantes socioeconômicos, baseando-se nas microrredes do APL.Com. Isto porque as organizações e interorganizações que atuam na atividade turística, nem sempre se localizam próximas do território (micro espacialidade) que se planeja. No entanto, pode influenciar ou, até mesmo, interferir política e economicamente, como as redes nacionais e internacionais de 
certificação de turismo sustentável ou comunitário (SAMPAIO; FERNANDES; PHILIPPI JR, 2010).

Consequentemente, as etapas 4 - Questões Estratégicas - e 5 - Ações Estratégicas reproduzem os problemas mais importantes e suas respectivas soluções para viabilizar efetivamente o APLTur.Com. As etapas 6 - Gerência por Projetos -, 7 - Gerência Institucional e 8 - Indicadores de Sustentabilidade - são ferramentas que se utilizam de estruturas matriciais, típicas da gestão interorganizacional, para implantar e monitorar projetos que atendam a estrutura formada pelo conjunto de microrredes do APLTur.Com. Estas etapas completam o processo político e proporcionam a gestão dos problemas locais agrupados e organizados nos projetos; garantem a participação democrática e organizada, e possibilitam medir a qualidade e efetividade do processo e dos seus resultados (SAMPAIO; FERNANDES; PHILIPPI JR, 2010).

\section{METODOLOGIA}

Para o alcance dos objetivos propostos, utilizou-se de pesquisa descritiva, através da abordagem sobre APLTur.Com, aplicando as etapas $\mathbf{1}$ e $\mathbf{3}$ da metodologia PEC/SiGOS/APLTur.Com ${ }^{3}$, deixando para um outro momento a aplicação das demais. Para tanto, realizou-se uma oficina com membros comunitários das comunidades do Sudoeste da Microbacia do Rio Sagrado, os quais foram convidados a participar da oficina com duas semanas de antecedência. Assim, 12 membros da comunidade demonstraram interesse em participar do trabalho e inscreveram-se para a oficina, a qual aconteceu nos dias 16 e 17 de outubro de 2009, tendo como objetivo a discussão de conceitos centrais sobre arranjos produtivos com a comunidade e, também, a identificação do papel de cada ator na estruturação do arranjo.

Embora a aplicação do PEC/SiGOS/APLTur.Com retrate um momento pontual, ela se contextualiza a partir de projeto de fôlego, intitulado Zona de Educação para o Ecodesenvolvimento (ZEE), na qual vem sendo implantado no território desde 2006, tendo gerado cerca de vinte trabalhos, entre eles de conclusão de curso de graduação e mestrado, e relatórios técnicos-científicos para agências de fomento. A ZEE tem como visão filosófica repensar as relações assimétricas entre homem-natureza e as que reproduzem entre os

\footnotetext{
${ }^{3}$ Para maior detalhamento da metodologia PEC-SiGOS/APL.Com, ver Sampaio, Fernandes, Philippi Jr., (2010).
} 
próprios homens nas suas relações sociais. Ela se inspira numa proposta de pesquisaação participativa, na qual a população local não aponta apenas as demandas da comunidade como também contribui nas soluções a partir de conhecimento local, complementado com o conhecimento cientifico (SAMPAIO, HENRÍQUEZ, MANSUR, prelo).

A região Sudoeste da Microbacia é composta pelas comunidades rurais de Rio Sagrado de Cima, Canhembora, Brejumirim e Candonga, localizadas a $65 \mathrm{~km}$ de Curitiba (PR). A população é constituída aproximadamente por 520 famílias, sendo 270 famílias residentes, predominantemente pequenos proprietários rurais, e 250 famílias não-residentes, ou seja, proprietários de chácaras ou sítios de lazer. As comunidades estão organizadas através de duas associações, a Associação de Moradores do Rio Sagrado (AMORISA) e a Associação Comunitária Candonga, tendo a primeira entre outras finalidades a da gestão do abastecimento da água. A segunda associação tem como finalidade principal a agroindustrialização de produtos in natura em sua sede (onde está instalada uma cozinha comunitária) e desenvolve ações com o intuito de atuar na defesa dos interesses sociais, culturais e econômicos das famílias associadas (ALVES, 2008; ZECHNER, 2007). Nesse sentido, após análise, interpretação e avaliação dos resultados, o trabalho teve como direcionamento principal a apresentação dos resultados obtidos na pesquisa realizada, que são apresentados a seguir.

\section{DISCUSSÃO E RESULTADOS}

Por meio da abordagem sobre Arranjos Socioprodutivos de Base Comunitária, baseada na metodologia PEC/SiGOS/APL.Com, realizou-se oficina com alguns membros comunitários das comunidades da Microbacia do Rio Sagrado, nos dias 16 e 17 de outubro de 2009, tendo como objetivo a discussão do conceito de arranjo. A oficina contou com a participação de 12 atores locais, sendo a maioria destes participantes ativos do arranjo socioprodutivo. $\mathrm{O}$ item $5.1 \mathrm{a}$ seguir, apresenta os principais resultados obtidos na aplicação da etapa 1 da metodologia PEC/SiGOS/APL.Com, no que tange a construção do arranjo socioprodutivo de base comunitária do Rio Sagrado, com participação dos membros comunitários na sua estruturação. Já o item 5.2 contempla a etapa 3 da metodologia, por meio de uma avaliação qualitativa por parte dos participantes no que tange ao ambiente em que o arranjo está inserido, contemplando 
análises do ambiente interno (pontos fortes e fracos) e do ambiente externo (oportunidades e ameaças).

\subsection{RESULTADOS ETAPA 1: CONSTRUÇÃO DO ARRANJO SOCIOPRODUTIVO}

Como parte introdutória da oficina, foram apresentados conceitos sobre associativismo, cooperativismo, arranjos, arranjos produtivos locais, para finalmente abarcar o conceito de APLTur.Com. Para melhor compreensão do arranjo do Rio Sagrado, o trabalho baseou-se na matriz proposta por Sampaio, Fernandes e Philippi Jr. (2010) de forma que a comunidade pudesse identificar as atividades que configuravam o arranjo do Rio Sagrado.

Nesse sentido, conforme estudo desenvolvido por Zechner (2010) - baseado na matriz elucidada por Sampaio (2010) - o conjunto de atividades desenvolvidas no APLTur.Com do Rio Sagrado constitui uma matriz principal, também definida como Mater, representada pelas relações estabelecidas entre os atores e atividades locais, conforme demonstra a Figura 2 a seguir.

\begin{tabular}{c|c|c} 
& $\begin{array}{c}\text { Encadeamento Produtivo Vertical } \\
\text { Cozinha Comunitária }\end{array}$ & \\
\hline $\begin{array}{c}\text { Encadeamento Produtivo } \\
\text { Horizontal - apoio }\end{array}$ & $\begin{array}{c}\text { Microrrede Principal } \\
\text { Núcleo institucional do arranjo } \\
\text { FURB, Aliança Empreendedora, } \\
\text { EMATER }\end{array}$ & $\begin{array}{c}\text { Encadeamento Produtivo } \\
\text { Horizontal } \\
\text { Feiras de Trocas, Turismo } \\
\text { Comunitário e ARTRISA }\end{array}$ \\
\hline & $\begin{array}{c}\text { Encadeamento Produtivo Vertical } \\
\text { Turistas e moradores locais }\end{array}$ & \\
\hline
\end{tabular}

FIGURA 2 - MATRIZ MATER

FONTE: ZECHNER, 2010.

A microrrede principal, representada na parte central da matriz, abrange as relações de cooperação existentes entre os componentes que influenciam e se interrelacionam no arranjo. "É através do suporte institucional, seja através de organizações formais ou não, é que se estabelecem acordos, se compartilham informações [...] que beneficiam a existência do grupo, como um todo, do Rio Sagrado", complementa ZECHNER (2010, p. 99).

Os encadeamentos produtivos na ordem vertical estão relacionados com a comercialização dos bens e serviços do arranjo, ou seja, com o fornecimento e a distribuição. Assim, os encadeamentos à montante versam sobre a relação de fornecedores dos principais bens oferecidos, tendo como exemplo a atuação da Cozinha Comunitária na comunidade. Já o 
encadeamento produtivo vertical à jusante refere-se à distribuição dos bens e serviços do arranjo. Neste caso, pode ser mencionada a venda de produtos por parte dos residentes aos turistas que freqüentam o local (ZECHNER, 2010).

Os encadeamentos produtivos horizontais referem-se à terceirização não espúria, representados à esquerda e à direita da matriz, respectivamente. Sobressaem-se nestes encadeamentos as organizações que apóiam o arranjo, sendo a Universidade Regional de Blumenau (FURB) a primeira instituição a apoiar a localidade, firmando parcerias com diversas outras organizações desde 2006, contribuindo para a consolidação de uma relação de sucesso entre universidade e comunidade.

Ainda, como outro representante destas relações de terceirização não espúria, destaca-se a Feira de Trocas, organizada mensalmente pela comunidade com intuito de promover a idéia de trocas solidárias, sem a utilização do dinheiro, favorecendo laços de solidariedade e o diálogo entre os participantes. Além disso, o turismo comunitário exerce fundamental papel neste sentido, pois possibilita o fomento da economia local. A associação ARTRISA também desponta como importante multiplicadora da renda local, através da produção de peças artesanais que são vendidas para os próprios moradores e visitantes do local (ALVES, 2008; ZECHNER, 2010).

Conforme construção juntamente com os membros participantes da oficina, desmembrou-se a associação ARTRISA e a Cozinha Comunitária em matrizes separadas, valendo-se do mesmo modelo explicativo utilizado para a Matriz Mater proposta por Zechner (2010). Esta divisão das matrizes oportunizou que os atores locais pudessem vislumbrar o papel de cada atividade/ator/instituição na constituição do arranjo, e como estavam estabelecidas as relações destas organizações e/ou atividades em relação ao entorno.

\begin{tabular}{|c|c|c|}
\hline & $\begin{array}{l}\text { Encadeamento Produtivo Vertical } \\
\text { Fornecedores de ferro/aço situados } \\
\text { em Paranaguá e fornecedores de } \\
\text { material de apoio de Morretes. }\end{array}$ & \\
\hline \multirow[t]{2}{*}{$\begin{array}{c}\text { Encadeamento Produtivo } \\
\text { Horizontal - apoio } \\
\text { Aliança Empreendedora e FURB. }\end{array}$} & $\begin{array}{c}\text { Microrrede Principal } \\
\text { ARTRISA }\end{array}$ & $\begin{array}{c}\text { Encadeamento Produtivo } \\
\text { Horizontal - (tercerização não } \\
\text { espúria) Associação Comunitária } \\
\text { Candonga. } \\
\end{array}$ \\
\hline & $\begin{array}{l}\text { Encadeamento Produtivo Vertical } \\
\text { Mercado consumidor localizado em } \\
\text { Morretes, Antonina e Paranaguá e } \\
\text { turistas do Rio Sagrado. }\end{array}$ & \\
\hline
\end{tabular}

FIGURA 3 - MATRIZARTRISA

FONTE: ZECHNER (2010) 
Enquanto microrrede principal, a ARTRISA constitui encadeamentos produtivos verticais à montante, com fornecedores de matéria-prima situados no centro de Morretes e em Paranaguá; já à jusante, relaciona-se com o mercado consumidor através de feiras realizadas em Morretes, Antonina e Paranaguá, além dos turistas que visitam o Rio Sagrado. Conforme o arranjo da ARTRISA construído juntamente com os membros comunitários durante a oficina, no que tange aos encadeamentos produtivos horizontais, as instituições de apoio da ARTRISA são a Aliança Empreendedora e a FURB, enquanto que no encadeamento produtivo horizontal, referindo-se à terceirização não espúria, encontra-se a Associação Comunitária Candonga.

Dando continuidade a oficina, foi trabalhada a construção da matriz da Associação Comunitária Candonga, conforme sugere a Figura 4 a seguir.

\begin{tabular}{c|c|c} 
& $\begin{array}{c}\text { Encadeamento Produtivo Vertical } \\
\text { Agricultores familiares e artesãos } \\
\text { locais }\end{array}$ & Ticrorrede Principal \\
$\begin{array}{c}\text { Encadeamento Produtivo } \\
\text { Horizontal - apoio } \\
\text { FURB, LaGOE, EMATER e } \\
\text { AMORISA }\end{array}$ & $\begin{array}{c}\text { Associação Comunitária Candonga } \\
\text { (Cozinha Comunitária) }\end{array}$ & $\begin{array}{c}\text { Horizontal } \\
\text { Feiras de Trocas }\end{array}$ \\
\hline & $\begin{array}{c}\text { Encadeamento Produtivo Vertical } \\
\text { Consumidores locais } \\
\text { Mercado consumidor de Morretes e } \\
\text { Antonina } \\
\text { Turistas }\end{array}$ & \\
\hline
\end{tabular}

FIGURA 4 - MATRIZ ASSOCIAÇÃO COMUNITÁRIACANDONGA FONTE: Adaptado de ZECHNER (2010).

Quando considerada microrrede principal, a Associação Comunitária Candonga (representada pela Cozinha Comunitária) possui como encadeamento produtivo vertical à montante as relações com os artesãos e agricultores familiares locais, os quais representam a mão de obra, e consequentemente, atores fundamentais para a matriz. Já como encadeamento produtivo vertical à jusante, tem-se os consumidores locais e da região do entorno de Morretes e Antonina, bem como os turistas que visitam a localidade. As Feiras de Trocas que acontecem na comunidade podem ser compreendidas como uma forma de terceirização não espúria, pois possibilitam a divulgação dos produtos artesanais produzidos na Cozinha Comunitária. 


\subsection{RESULTADOS ETAPA 3: ANÁLISE DO AMBIENTE INTERNO E EXTERNO}

Após a identificação de cada ator na composição do arranjo, por meio da aplicação da metodologia PEC/SiGOS/APLTur.Com, alguns questionamentos foram aplicados em busca de possibilitar uma maior compreensão da organização do arranjo socioprodutivo de base comunitária local. A partir do momento que cada membro comunitário identificou seu papel no arranjo, foram descritos quais os pontos fortes e os pontos fracos, bem como as oportunidades e ameaças que potencialmente influenciariam no bojo do APLTur.Com do Rio Sagrado.

Conforme afirma Sampaio, Fernandes e Philippi Jr. (2010), no processo de administração e controle dos ambientes que influenciam uma organização se faz necessário identificar as oportunidades e ameaças vinculadas ao desenvolvimento bem como analisar quais as forças e fraquezas podem influenciar no desempenho da instituição e no seu planejamento. Neste sentido, o ambiente interno, neste caso do objeto de estudo do Sudoeste da Microbacia do Rio Sagrado, pode ser controlado pelos próprios residentes, uma vez que ele é resultado das estratégias de atuação definidas pelos próprios moradores da localidade. Já o ambiente externo está totalmente fora do controle da comunidade. Mas, apesar de não poder controlá-lo, a comunidade deve conhecê-lo e monitorá-lo com frequiência, de forma a aproveitar as oportunidades potenciais para o local e, ao mesmo tempo, evitar as ameaças.

A seguir, os quadros 1 e 2 apontam os principais resultados obtidos nesta atividade. Conforme ilustram os quadros, a descrição das limitações e das características positivas por parte dos membros comunitários contextualizaram os ambientes externo e interno da localidade, tomando por base a opinião e compreensão dos mesmos sobre os fatores que consideraram influentes sob os ambientes. Assim, para promover a estruturação e construção do Arranjo Socioprodutivo de Turismo de Base Comunitária, o cruzamento dessas variáveis propiciou uma visão preliminar a respeito de estratégias a serem adotadas para o desenvolvimento local. 


\begin{tabular}{|c|c|c|}
\hline \multicolumn{3}{|c|}{ AMBIENTE INTERNO } \\
\hline & PONTOS FORTES & PONTOS FRACOS \\
\hline $\begin{array}{l}\text { Organização } \\
\text { Comunitária }\end{array}$ & $\begin{array}{l}\text { - Força Jovem; } \\
\text { - Associações locais. }\end{array}$ & $\begin{array}{l}\text { - Falta de comunicação entre os moradores } \\
\text { (nem todos possuem telefone); } \\
\text { - Não há internet; } \\
\text { - Falta de interesse em participar das } \\
\text { atividades na comunidade. }\end{array}$ \\
\hline $\begin{array}{l}\text { Associação } \\
\text { Comunitária } \\
\text { Candonga e } \\
\text { Biblioteca } \\
\text { Comunitária }\end{array}$ & $\begin{array}{l}\text { - Local para realização de reuniões e } \\
\text { encontros comunitários; } \\
\text { - Infraestrutura para produção de produtos } \\
\text { artesanais como doces, pães, bolachas } \\
\text { caseiras e conservas; } \\
\text { - Acesso à informação e conhecimento } \\
\text { através da biblioteca. }\end{array}$ & $\begin{array}{l}\text { - Falta de apoio dos associados; } \\
\text { - Inadimplência referente à mensalidade. }\end{array}$ \\
\hline ARTRISA & $\begin{array}{l}\text { - Oportunizar a realização de cursos de } \\
\text { aperfeiçoamento; } \\
\text { - Melhorias na infraestrutura local. }\end{array}$ & $\begin{array}{l}\text {-Falta de espaço para exposição dos } \\
\text { produtos; } \\
\text { - Falta de cursos para melhoria; } \\
\text { - Poucos sócios. }\end{array}$ \\
\hline AMORISA & $\begin{array}{l}\text { - Abastecimento de água de diversas } \\
\text { residências; } \\
\text { - Atendimento de demandas dos sócios e da } \\
\text { comunidade. }\end{array}$ & $\begin{array}{l}\text { - Pouca participação dos sócios nas } \\
\text { reuniões; } \\
\text { - Inadimplência referente às mensalidades. }\end{array}$ \\
\hline $\begin{array}{l}\text { Turismo } \\
\text { Comunitário }\end{array}$ & $\begin{array}{l}\text { - Oportunidade de geração de renda e } \\
\text { emprego; } \\
\text { - Hospedaria; } \\
\text { - Feira de Trocas; } \\
\text { - Vivências (engenho da farinha e do café, } \\
\text { artesanato com cipó imbé, fibra de } \\
\text { bananeira); } \\
\text { - Atrativos naturais. }\end{array}$ & $\begin{array}{l}\text { - Falta de divulgação das Feiras de Trocas; } \\
\text { - Falta de divulgação dos produtos e } \\
\text { serviços locais; } \\
\text { - Falta de envolvimento de moradores } \\
\text { locais na atividade. }\end{array}$ \\
\hline
\end{tabular}

QUADRO 1 - AMBIENTE INTERNO (PONTOS FORTES/FRACOS)

FONTE: OS AUTORES.

A construção dos arranjos locais, juntamente com a análise dos ambientes que caracterizam o Rio Sagrado, propiciou o conhecimento das questões mais emergentes de reestruturação para a promoção e o fortalecimento das atividades socioprodutivas locais (artesanato, turismo etc.), com o objetivo de maximizar as forças e oportunidades e minimizar as fraquezas e ameaças.

No que tange a análise sobre os Pontos fortes x Oportunidades, entende-se como fator potencial o interesse de membros comunitários em trabalhar coletivamente, a fim de alcançarem resultados positivos para todos os envolvidos das atividades do arranjo. Ainda, a localidade dispõe de infraestrutura para a viabilização de produtos artesanais, como a Cozinha Comunitária (Associação Comunitária Candonga) e a Associação de Artesãos (ARTRISA), o que possibilita que se desenvolvam social e economicamente.

No que se refere aos Pontos fracos x Ameaças, se faz necessário maior participação e articulação por parte do poder público em relação à comunidade, uma vez que não que não há 
comprometimento em atender questões de infraestrutura básica para o local. Além disso, o envolvimento da comunidade no processo de planejamento e tomada de decisão, através da mobilização e participação em reuniões e projetos, podem fomentar o desenvolvimento local.

\begin{tabular}{|c|c|c|}
\hline \multicolumn{3}{|c|}{ AMBIENTE EXTERNO } \\
\hline & OPORTUNIDADES & AMEAÇAS \\
\hline Apoio/Parcerias & $\begin{array}{l}\text { - UFPR; FURB; Senai; } \\
\text {-Emater; Aliança Empreendedora; Tecpar. }\end{array}$ & - \\
\hline $\begin{array}{c}\text { Contexto } \\
\text { Ambiental }\end{array}$ & $\begin{array}{l}\text { - Biodiversidade; natureza; belas } \\
\text { paisagens; atrativos naturais; } \\
\text { - Comunidade inserida em uma Área de } \\
\text { Preservação Ambiental (APA). }\end{array}$ & $\begin{array}{l}\text { - Excesso de chuvas; } \\
\text { - Umidade (causa de bolor na fibra de } \\
\text { bananeira). }\end{array}$ \\
\hline Poder Público & $\begin{array}{l}\text { - Oportunizar a realização de cursos de } \\
\text { aperfeiçoamento; } \\
\text { - Melhorias na infraestrutura local. }\end{array}$ & $\begin{array}{l}\text { - Falta de apoio do poder público; } \\
\text { - Falta manutenção das estradas de acesso; } \\
\text { - Telefones públicos sem manutenção. }\end{array}$ \\
\hline
\end{tabular}

QUADRO 2 -AMBIENTE EXTERNO (OPORTUNIDADES/AMEAÇAS)

FONTE: OS AUTORES.

Outro fator importante a ser considerado é que mesmo com a falta de participação, seja pela indisponibilidade de tempo ou até mesmo pela falta de interesse por parte dos residentes, existe a sensibilidade de alguns moradores em participar e tomar a frente do processo de estruturação do arranjo. Neste sentido, torna-se imprescindível um grande esforço e vontade de todos os agentes em colaborar e muitas vezes suprimir interesses particulares, buscando alcançar um objetivo comum, que favoreça a todos os envolvidos.

\section{CONSIDERAÇÕES FINAIS}

A perspectiva de um APLTur.Com aposta no princípio de que pode existir solidariedade na economia entre os que se associam para produzir, comercializar e consumir produtos, inspirados na perspectiva da ecossocioeconomia. Essa afirmação se baseia principalmente a partir da aplicação da metodologia PEC e SiGOS, com intuito de construir um conhecimento participativo que fomente a consolidação de novas vocações e potencialidades sociais, econômicas e ecológicas.

No que tange a análise dos ambientes interno e externo que constituem e influenciam o arranjo, a partir da discussão incitada, sugere-se que haja maior diálogo e participação dos interessados em buscar alternativas diante das dificuldades encontradas, procurando eliminar ou minimizar ao máximo as fragilidades e monitorar as ameaças. Assim, sugere-se que pesquisas 
complementares na área de estudo sejam desenvolvidas para que novas propostas de planejamento sistêmico e de ações integradas fomentem o desenvolvimento local.

Neste contexto, entende-se que o fomento da experiência do APLTur.Com na localidade possibilita que a rede de socioempreededores individuais e coletivos, apoiados devidamente, possam compreender a complexidade e a singularidade da economia comunitária na ocasião que está se insere na economia de mercado, para que sua lógica/racionalidade não seja cooptada.

O arranjo se bem planejado e governado pode ser um oportunidade de valorizar as comunidades tradicionais e seus modos de vida e ainda refletir sobre o ordenamento territorial de acordo com o marco regulatório estatal e territorial, o que o torna também um laboratório de experimentações.

O Arranjo se estabelece na ocasião que ele possui identificação com o território. Seu apelo se justifica, ainda mais, diante das perspectivas impostas pelo que a mídia vem chamando de aquecimento global. Ou seja, não há como deixar de aprender com modos de vida mais sustentáveis, isto é, onde o APLTur.Com atua.

O APLTur.Com tem como maior desafio sua institucionalização, não apenas na microbacia do Rio Sagrado, mas no litoral do Paraná. O que se espera ainda é avançar na discussão sobre as possibilidades na articulação entre urbano e rural, o entendimento do rural como não sendo apenas agrícola, e as especificidades do ambiente costeiro.

\section{REFERÊNCIAS}

ALBAGLI, S.; BRITO, J. Arranjos produtivos locais. RedeSist, 2002. Disponível em: <http://www.ie.ufrj.br/redesist>. Acesso em: 10/05/2009.

ALVES, F. K. Arranjo socioprodutivo de base comunitária. Dissertação Programa de Pósgraduação em Administração. Universidade Regional de Blumenau, 2008.

BECKER, B. K.; LÉNA, P. Pequenos empreendimentos alternativos na Amazônia. In: LASTRES, H. M. M.; CASSIOLATO, J. E.; MACIEL, M. L. (Orgs.). Pequena empresa: cooperação e desenvolvimento local. Rio de Janeiro: Relume Dumará: UFRJ, Instituto de Economia, 2003.

CASSIOLATO, J. E.; SZAPIRO, M. Aglomerações geográficas e sistemas produtivos e de inovação. Rede de Pesquisa em Sistemas Produtivos e Inovativos Locais. RJ. IE/UFRJ, 2002. Disponível em: <http://redesist.ie.ufrj.br>. Acesso em: 08/05/2009. 
CORIOLANO, L. N. C. Os limites do desenvolvimento e do turismo. In: CORIOLANO, L. N. M. T. O Turismo de inclusão e o desenvolvimento local. Fortaleza: FUNECE, 2003. p. 13-27.

SACHS, I. Ecodesenvolvimento. São Paulo, SP: Vértice, 1986.

SAMPAIO, C. A. C. Gestão que privilegia uma outra economia. Blumenau: EDIFIRB, 2010.

SAMPAIO, C. A. C.; OYARZÚN, E.; SOUZA, M. S. de; CÁRCAMO, C.; MANTOVANELI Jr, O. Arranjo socioprodutivo de base comunitária: análise comparativa de experiências de turismo comunitário no Brasil e no Chile. Revista de Negócios, v. 10, p. 288-301, 2005.

SAMPAIO, C. A. C.; MUNDIM, R. S. A.; DIAS, A. Arranjo produtivo local voltado para a promoção do turismo educativo na área da lagoa de Ibiraquera (Garopaba e Imbituba - SC). In: ENTBL, 8. Curitiba, 2004. Anais ..., Curitiba, 2004.

SAMPAIO, C. A. C.; ZECHNER, T. C.; ALVES, F. K. O papel do turismo no arranjo socioprodutivo de base comunitária da microbacia do rio Sagrado. Revista Dynamis. Blumenau - SC, v. 1, p. 34-42, 2008.

SAMPAIO, C. A. C.; AZKARRAGA E. J.; ALTUNA, G. L.; FERNANDES, V. Pensando la experiencia de cooperativismo de Mondragón bajo la mirada de la ecosocioeconomía de las organizaciones In: ALTUNA, R.; GRELLIER, H.; URTEAGA, E. Cuestiones prácticas en la economía social globalizada. Oñati: Mondragón Bilduma (Universidad de Mondragón), 2010a.

SAMPAIO, C. A. C.; FERNANDES, V.; PHILIPPI JR, A. Planejamento e gestão de turismo sustentável: metodologias PEC \& SiGOS. In: RUSCHMANN, D. V. de M.; PHILIPPI JR, A. Gestão ambiental e sustentabilidade no turismo. Barueri (SP): Manole, 2010b, p. 151-171.

SAMPAIO, C. A. C.; HENRÍQUEZ, C.; MANSUR, C. (Org.). Turismo comunitário solidário e sustentável: da crítica às ideias e das ideias à pratica. Blumenau: Edifurb, prelo.

ZECHNER, T. C. Arranjo socioproduitvo de base comunitária, com ênfase no turismo comunitário: o caso da micro-bacia do rio Sagrado (Morretes, PR). Relatório Final de Estágio Supervisionado II (Curso de Graduação em Turismo e Lazer). Centro de Ciências Sociais Aplicadas, Universidade Regional de Blumenau, 2007.

ZECHNER, T. C. Arranjo socioprodutivo de turismo de base comunitária, com ênfase no turismo comunitário da microbacia do rio Sagrado (Morretes). Dissertação de Mestrado (Desenvolvimento Regional). Universidade Regional de Blumenau, 2010.

Recebido em: 02-08-2011.

Aprovado em: 02-09-2011. 